6. IGD. (2017). Designing, presenting and positioning front of pack nutrition labels: a best practice guide based on consumer research. https://www.igd.com/socialimpact/health/engaging-consumers/labelling/designing-front-of-pack-nutrition-labels (accessed March 2021).

\section{P25 BUILDING A COMMUNITY ADVISORY BOARD TO RESEARCH CLIMATE CHANGE IMPACTS ON CONSUMPTION OF FOOD BIODIVERSITY OF INDIGENOUS COMMUNITIES IN THE PERUVIAN AMAZON}

\begin{abstract}
${ }^{1}$ Carol Zavaleta-Cortijo*, 'Andrea Valdivia-Gago, ${ }^{1}$ Rosalia Montero, ${ }^{1}$ Rosa Silvera, ${ }^{2}$ Delfina Catip, ${ }^{2}$ Rocilda Nunta, ${ }^{3}$ Connie Fernandez-Neyra, ${ }^{4}$ Guillermo Lancha, ${ }^{4}$ Pedro Pizango, ${ }^{5}$ Juan-Pablo Aparco. ${ }^{1}$ Facultad de Salud Publica (FASPA), Universidad Peruana Cayetano Heredia, Lima, Peru; ${ }^{2}$ Programa Mujer, Asociacion Interetnica de Desarrollo de la Selva Peruana (AIDESEP), Lima, Peru; ${ }^{3}$ Hospital Santa Gema, Direccion Regional de Salud Loreto, Yurimaguas, Peru; ${ }^{4}$ Pueblo Shawi, Yurimaguas, Peru; ${ }^{5}$ Centro Nacional de Alimentacion y Nutricion, Instituto Nacional de Salud, Lima, Peru
\end{abstract}

\subsection{6/jech-2021-SSMabstracts. 114}

Background A sustainable planet for everyone requires improving the nutrition of minorities and historically excluded populations. Indigenous people in South America are among those more affected by multiple forms of malnutrition, and the Amazon ecosystem is increasingly experiencing dramatic changes including more frequent and intense extreme weather events. In the context of a research project aimed to investigate the potential of food biodiversity to protect Amazon Indigenous people nutrition in the light of more intense and severe flooding, we have created a Community Advisor Board $(\mathrm{CAB})$ to increase the impact of the project, and to provide with advice to conduct a meaningful and cultural adequate implementation of the project.

Methods One climatologist, two senior nutritionists (male and female) and two women Indigenous leaders, were invited to participated in the $\mathrm{CAB}$ through official letters by email. All except the climatologist, replied positively. As part of the first year we have developed three online working meetings (1 to 2 hrs each). The $\mathrm{CAB}$ have provided advice to adapt an online dietary assessment tool (myfood24), to perform a pilot study for creating a photo album of Indigenous food portions, and to advise on how to approach Indigenous communities nutritional needs during the still on going COVID-19 pandemic in the Peruvian Amazon.

Results Four critical points were highlighted by the CAB for increasing the impact of the project: 1) to seek to increase the resilience of Indigenous food diets to climate change for example by identifying what crops were 'climate resistant' according to Indigenous knowledge, 2) It was recommended to collect recipes that have protected indigenous communities during COVID-19 since 'food' was also used as 'medicine' among Indigenous people, 3) the investigation of food biodiversity informs Indigenous food resilience this was mentioned as being highly important to protect indigenous nutrition during extreme weather events and even during COVID-19, and 4) It was recognized that gender differences were important to consider because of biological differences between male and female, for food consumption (e.g. portion sizes and food distribution within households vary between sexes) and because women were the protectors and safeguarders of knowledge to produce and collect plants from the forest

Conclusion The $\mathrm{CAB}$ was stablished with two Indigenous and two non-Indigenous members. The $\mathrm{CAB}$ encouraged the researchers to share the data collected with other indigenous groups in the Amazon to increase their resilience to climate change and to inform peruvian authorities about the nutrition content of Indigenous foods

\section{P26 EXPLORING OPINIONS ABOUT A MINDFULNESS-BASED INTERVENTION FOR DISORDERED EATING AMONG UNIVERSITY STUDENTS: A QUALITATIVE STUDY}

${ }^{1}$ Ella Altair*, ${ }^{1}$ Eleni Karasouli, ${ }^{2}$ Caroline Meyer, ${ }^{1}$ Oyinlola Oyebode. ${ }^{1}$ Warwick Medical School, University of Warwick, Coventry, UK; ${ }^{2}$ Warwick Manufacturing Group, University of Warwick, Coventry, UK

\subsection{6/jech-2021-SSMabstracts.115}

Background It is not uncommon that university students may exhibit disordered eating behaviours because of the various challenging factors in their age-group. Research points to the high prevalence of subclinical eating disorders (EDs) that do not require clinical attention among young adults. We aimed to conduct a qualitative study among university students with subclinical EDs to explore students' attitudes and opinions about a potential mindfulness-based intervention.

Methods Six online focus groups and five interviews took place using Microsoft Teams among young adult students. Participants were recruited online through university mailing lists and were screened for subclinical EDs to ensure eligibility. Those requiring clinical attention were excluded. Discussions lasted 60-90 minutes and focused on reasons of disordered eating behaviours, acceptability of the proposed intervention themes and students suggestions and opinions about the intervention. The study was approved by Biomedical \& Scientific Research Ethics Committee (BSREC) of the University of Warwick.

Results 23 participants from seven departments took part in the study, most of them were white females aged between 18 and 22. Results revealed the acceptability of mindfulness intervention as well as intuitive eating. Students' main reasons for disordered eating were mental health challenges, especially stress; and social influences, especially social media. University lifestyle elements were believed to have minimal impact on the occurrence of ED behaviours. Students preferred the intervention to be with a group respecting confidentiality, focused on practicals, personalized where possible, encouraging participants to attend through providing effective solutions yielding a change in their eating behaviours or through the reassurance of being with a group of participants going through similar experiences.

Conclusion Mindfulness-based intervention might be applied among university students with subclinical EDs. Participants might prefer different kinds of mindfulness practices such as sitting meditations or moving meditations. Other approaches may need to be combined with mindfulness for those who believe this is needed, such cognitive behavioural therapy practices. Interventions might consider creating a reassuring and confidential space for participants through a group, grouping participants with similar behaviours together, creating a helpful environment to commit to the practices such as providing a specific form of practice and a progress checker. University-student participants with sub-clinical EDs might be knowledgeable about healthy eating and EDs and willing to improve their eating behaviours but do not know where/how to start. 